\title{
Control of Ecotoxicants Content in Feed Additives and Veterinary Pharmacological Products
}

\author{
Georgiy Aleksandrovich Zhorov * , Lyubov Lvovna Zakharova, Vasiliy Ivanovich Dorozhkin and Elizaveta Arkadievna \\ Denisova
}

All-Russian Research Institute for Veterinary Sanitation, Hygiene and Ecology - Branch of «Federal Scientific Center - K.I. Skryabin, Ya.R. Kovalenko All-Russian Research Institute of Experimental Veterinary Medicine, Russian Academy of Sciences», Moscow, Russia

\begin{abstract}
The article is devoted to the control of ecotoxicants content in mineral and organic substances of natural and artificial origin used in the production of feed additives and pharmacological veterinary agents. In the context of the growing technogenic load on the environment, the probability of detecting increased background levels of natural and technogenic ecotoxicants in mineral and organic raw materials for the production of feed additives and veterinary products increases significantly. In this regard, more attention should be paid to the study of substances of artificial origin with a minimum content of toxic and ballast components, as well as substances that have undergone technological processing to reduce their natural level of ecotoxicants. According to modern data, amorphous silicon dioxide is an effective, safe, economically available sorbing agent and it should be considered as a promising sorption-detoxifying agent for application under the influence of xenobiotics that differ in the toxicological action mechanism on the animal organism.
\end{abstract}

\section{Introduction}

In regions with a high anthropogenic load, farm animals are exposed to long-term systematic exposure to technogenic ecotoxicants. In such conditions, the production of animal products that meet the regulatory requirements and ensure the veterinary and sanitary welfare of animals is impossible without the use of multifunctional agents of multidirectional activity both against xenobiotics of radiation and chemical nature, and the negative consequences of their impact on the organism.

The extensive list of pharmacological agents and biologically active substances (BAS) makes it possible, under the specific conditions of agricultural production, to develop and adjust the compositions of detoxicants and BAS in the form of feed additives (FA) to reduce the xenobiotics intake from the diet components into the animal organisms, while maintaining the presence of the main active substances for detoxification and maintaining normal vital functions of the organism (Table 1). It should be noted that the division of such pharmacological agents and additives into groups according to the action mechanism is often conditional since they exhibit a multifaceted effect on ecotoxicants, various metabolic processes, tissues, organs and the organism as a whole.

Due to the fact that substances used as detoxifying agents, BAS and FA, as well as feed, water and air, can act as a source of xenobiotics in the organism, affect the quality and safety of animal products and, ultimately, the human organism, it is of scientific and practical interest to determine the levels of background ecotoxicants content of radiation and chemical nature.

\section{Results}

For an objective assessment of the effectiveness and safety of veterinary pharmacological agents and feed additives application, including sorption-detoxifying and biologically active substances, it is necessary to control the background levels of ecotoxicants, primarily normalized technogenic xenobiotics. This applies particularly to preparations and additives produced from raw materials of natural origin, for example, natural minerals (zeolites, bentonite, vermiculite, perlite), organic substances (activated carbons, humates, sapropels, etc.), preparations of biological origin derived from plant and animal organisms (lignin, pectins, herbal medicines, chitin derivatives and many others).

The importance of the issue is indicated by the fact that, for example, such minerals as vermiculite, perlite and bentonite are allowed to be included in the diet of animals in the production of "organic food" (SanPiN 2.3.2.1078-01, p. 6.8.13), which are positioned as products obtained in environmentally friendly conditions using technologies that ensure the production of food products from raw materials without the use of pesticides and other plant protection products, chemical fertilizers, growth stimulants and fattening of animals, antibiotics, hormonal and veterinary drugs, GMOs and not subjected to ionizing radiation treatment.

\footnotetext{
Corresponding author: geo_geo@mail.ru
} 
Table 1. The main groups of detoxifying and biologically active substances

\begin{tabular}{|c|c|}
\hline $\begin{array}{c}\text { Main groups } \\
\text { of active ingredients }\end{array}$ & $\begin{array}{l}\text { The list of detoxifying and } \\
\text { biologically active substances }\end{array}$ \\
\hline $\begin{array}{l}\text { Mineral and organic sorbents of multifunctional } \\
\text { and selective action, ion-exchange, complexing } \\
\text { substances - compounds of various chemical } \\
\text { structures of natural and synthetic origin and } \\
\text { preparations based on them. They have antitoxic } \\
\text { properties against a wide range of toxicants, } \\
\text { including heavy metals and radioactive substances }\end{array}$ & $\begin{array}{l}\text { ferrocyanides (ferrocin, ferrocin-2, bifezh, HG-90, HG-90-Sr-TM, CIIOM, } \\
\text { etc.); zeolites (litovit, shivirtuin, pegasine, glauconite, litosorb, irlite, hongurin, } \\
\text { sahaptin, zeochol, humolite, permait, ecos), bentonite, vermiculite, zoo-verad, } \\
\text { amadeit, perlite, vitartil, primikor, diatomite (opal, tripolite); silicon-containing } \\
\text { preparations (amorphous silicon dioxide, polysurmin, enterosgel, polysorb, } \\
\text { white coal, noolit, etc.); carbon sorbents (carbolene, carboctin, gastrosorb, } \\
\text { SKN, SUGS, SKAN, vaulen, actilen, microsorb-P, zoosorb, zoocarb, etc.); } \\
\text { lignin-containing sorbents (polyphepan, pheocarpin, etc.); natural or modified } \\
\text { chitin (chitin and chitosan), succinate, chitan, chitin-melanin complex) }\end{array}$ \\
\hline $\begin{array}{l}\text { Antioxidant compounds are substances of various } \\
\text { chemical nature that have antioxidant properties. } \\
\text { They bind and neutralize free radicals, xenobiotics } \\
\text { and endogenous toxins, increase the } \\
\text { radioresistance of the organism }\end{array}$ & $\begin{array}{l}\text { sulfur and sulfur-containing compounds: elemental sulfur, sodium thiosulfate, } \\
\text { endogenous (glutathione, ergothioneine, lipoic acid, cysteine, cystine, } \\
\text { thioredoxins, metallothioneins) and synthetic thiols (unitiol, } \\
\text { dimercaptosuccinic acid, penicillamine, cystamine, mercamine, etc.); } \\
\text { tocopherols, carotenoids, ubiquinones, flavonoids, gallates, ascorbic acid; } \\
\text { selenium (selenium-active, cefacel, sodium selenite, E-selenium, DAFS-25, } \\
\text { etc.); enzymes (glutathione peroxidase, superoxide dismutase) }\end{array}$ \\
\hline $\begin{array}{l}\text { Immunomodulators (immunocorrectors) with } \\
\text { stimulant properties }\end{array}$ & $\begin{array}{c}\text { polyoxidonium, immunophane, gala-vet, roncoleukin, succinic acid, } \\
\text { phosprenyl, etc. natural and synthetic compounds }\end{array}$ \\
\hline $\begin{array}{l}\text { Feed additives - additional diet components } \\
\text { containing a complex of vital elements, } \\
\text { carbohydrates, vitamins and BAS }\end{array}$ & $\begin{array}{c}\text { complexes of vitamins and deficient micro and macro-nutrients, amino acids, } \\
\text { prebiotics and probiotics, etc. BAS and additives (kladez, tsamax, felucene, } \\
\text { gemovit-plus, stressmix, laricarvit, vitasol, etc.); humic substances (ligfol, } \\
\text { humavit, lignohumate, edagum, gumadapt, etc.) }\end{array}$ \\
\hline
\end{tabular}

The relevance of control is particularly high for feed additives and preparations produced in regions characterized by an increased environmental risk associated with the introduction of anthropogenic ecotoxicants of a chemical or radiation nature into the environment. These include endemic zones with an abnormally high content of toxic elements (TE) or radioactive substances (RS), industrial areas with developed mining and production activities, territories where technological accidents or precipitations have occurred, and agro-industrial regions with the active application of pesticides and fertilizers. Areas of pollution with different compositions and levels of ecotoxicants may overlap in space, partially or completely overlapping one another, which significantly increases the risk of combined effects of ecotoxicants that are more dangerous to humans and animals than separate ones.

As an example of the combined anthropogenic pollution of the territories by RS and TE, we can cite the Ural economic region, which occupies one of the leading places in terms of total emissions. As a result of radiation accidents at the Mayak chemical plant, the East Urals Radioactive Trace was formed (Chelyabinsk, Sverdlovsk, Kurgan regions), the main radioecological danger of which is associated with the release of ${ }^{90} \mathrm{Sr}$. In addition, numerous enterprises of the metallurgical, mining, and fuel and energy industries are located in the region, which is a pollution source with RS, TE, fluorine, and many other ecotoxicants.

More than that, in the territory of the Urals, minerals extraction activities are taking place that is also used in animal husbandry, as mineral sorbents and feed additives, for example, diatomites obtained in the Artemovsky ("Ural Composite" LLC) and Kamyshlovsky districts ("Ural Diatomite Company"
LLC) of the Sverdlovsk region, glauconite of the Karinsky deposit of the Chelyabinsk region.

Natural mineral sorbents, such as zeolites and bentonite clays, have a complex chemical composition, contained 30 to 40 elements, including physiologically significant macro- and microelements, among which are phosphorus, potassium, calcium, iron, copper, manganese, cobalt, and molybdenum. The largest specific gravity in the composition of zeolites is occupied by oxides of silicon, aluminum, iron, calcium, magnesium, sodium, and potassium. Enriching the diet with mineral sorbents and additives improves the use of feed, live weight gain, livestock safety, increases the level of metabolic processes and has a positive effect on the physiological state of animals [1].

At the same time, natural minerals simultaneously contain both natural and anthropogenic TE and RS, the composition and content levels of which can vary significantly depending on the place of extraction. For example, lead, mercury, arsenic, cadmium, strontium, and fluorine were found in the Shivyrtuy, Kholinsky, and Badinsky zeolite-containing deposits (Trans-Baikal Territory of the Russian Federation). In the studied shivyrtuin samples, the detected TE content exceeded the maximum residues levels (MRL) specified in TU 10RSFSR 359-91: cadmium - 0.16, lead - 0.3, arsenic 1.7 and mercury $-11.3 \%$ in samples. The same zeolites contain isotopes of uranium, radium, thorium, potassium, rubidium, and strontium [2].

The results of the study by V.I. Kovalenko and O.N. Prokofiev (1991) showed that the specific activity of ${ }^{238} \mathrm{U}$ in different zeolite-containing deposits varies from $26 \mathrm{~Bq} / \mathrm{kg}$ (Lyutogskoe deposit) to $70 \mathrm{~Bq} / \mathrm{kg}$ (Pegasskoe deposit); the specific activity of ${ }^{232} \mathrm{Th}$ is changed from $22 \mathrm{~Bq} / \mathrm{kg}$ (Shivyrtuy deposit) to $49 \mathrm{~Bq} / \mathrm{kg}$ (Pegasskoe 
deposit). The specific activity of ${ }^{40} \mathrm{~K}$ varies in the range from 200 to $930 \mathrm{~Bq} / \mathrm{kg}$ [3].

According to Yu.V. Pavlenko (1991), when shivyrtuin is included in the diet, the maximum mass fraction of absorbed TE from their total amount in the given mineral is: for lead - up to $5 \%$, for cadmium, fluorine, and arsenic - up to $20 \%$, for mercury - no more than $60 \%$. The results obtained in the model experiments indicate the possibility of the aluminum transition from zeolites to the gastrointestinal electrolyte $[4,5]$.

The intake of these toxicants together with the administrated preparations and their subsequent release in the gastrointestinal tract during ion exchange may be one of the reasons for the presence of biological aggressiveness signs in shivyrtuin (cytotoxic, mutagenic, and hemolytic activity), including carcinogenic properties that were previously detected in erionite. The possibility of toxic effects (mutagenic, carcinogenic, dystrophic changes of internal organs) accumulation in the animal organisms with an intragastric intake of zeolites was noted [6, 7].

It has been shown in experiments with rats that zeolite tuffs used as food additives actively invade chemical homeostasis and exhibit the properties of small or moderate stimuli, causing changes at the cellular and tissue levels of a predominantly catabolic nature. This makes the problem of cleaning tuffs from toxic substances more urgent and requires more balanced assessments of the zeolites effect on the human and animal organisms [8].

Sapropels are natural multi-layered geo-organic bottom sediments of freshwater reservoirs, which for a long period of time were formed from dead aquatic vegetation, plankton, animal remains, and soil humus particles. In terms of the composition of the components, they represent an analogue of humates in a colloidal state, contain a large number of organic substances and are a source of micro- and macroelements and other BAS, so they are used as feed additives. However, sapropels can accumulate pollutants (metals, petroleum products, pesticides, etc.), becoming a secondary pollution source, limiting or making them completely unsuitable for application [9-11].

Equally dangerous is ecotoxicants accumulation (heavy metals, pesticides, radionuclides, nitrites, nitrates, benzpyrene, fluorides, and many other compounds) in organic substances of natural origin used as medicines and biologically active additives. Since they are mainly used not regularly and in limited doses, the components of medicines may represent an additional source of xenobiotics in the human and animal organisms as well as in the manufactured products. Therefore, to ensure the safety of medicines obtained from substances of natural origin and plant raw materials, it is necessary to determine the ecotoxicants content, which are among the priority pollutants of the biosphere, primarily cadmium, lead and mercury [12].

Confirmation of the need for control was received in 2020-2021 in the laboratory of pharmacology and toxicology of the All-Russian Scientific Research Institute for Veterinary Sanitation, Hygiene and Ecology
- Branch of the Federal State Budget Scientific Institution "Federal Scientific Centre VIEV" the results of radiometric studies to determine the content of technogenic and natural radioactive isotopes $\left({ }^{90} \mathrm{Sr},{ }^{137} \mathrm{Cs}\right.$, ${ }^{40} \mathrm{~K},{ }^{226} \mathrm{Ra},{ }^{232} \mathrm{Th}$ ) in several feed additives, sorptiondetoxifying and biologically active substances and preparations. More than 30 samples were examined, including zeolites of various deposits, diatomite, vermiculite, perlite, shungite, radionite, amorphous silicon dioxide, white clay, polyphepan, lignohumate, some combined detoxicants, BAS and feed additives.

In the studied samples, the ${ }^{137} \mathrm{Cs}$ content did not exceed the standard level $(370 \mathrm{~Bq} / \mathrm{kg})$ and ranged from < 3 to $(40 \pm 7) \mathrm{Bq} / \mathrm{kg}$. However, about $43 \%$ of the samples had a specific activity level of ${ }^{90} \mathrm{Sr}$, exceeding the allowed level specified by the "Instruction on radiological control of feed quality" (No. 13-7-2 / 216 of $01.12 .1994)$. Thus, the specific activity of radiostrontium in the perlite sample reached $(137 \pm 9) \mathrm{Bq} / \mathrm{kg}$, which is almost 3 times higher than the limit of $50 \mathrm{~Bq} / \mathrm{kg}$ established for mineral feed additives. Similar results ${ }^{90} \mathrm{Sr}$ were obtained for shungite $(121 \pm 12) \mathrm{Bq} / \mathrm{kg}$ (Table 2).

Table 2. Specific activity of technogenic radionuclides $\left({ }^{90} \mathrm{Sr}\right.$,

${ }^{137} \mathrm{Cs}$ ) in samples of mineral and organic sorbents and BAS

\begin{tabular}{|l|c|c|}
\hline \multirow{2}{*}{\multicolumn{1}{c|}{$\begin{array}{c}\text { Studied } \\
\text { samples }\end{array}$}} & \multicolumn{2}{c|}{ Specific activity, Bq/kg } \\
\cline { 2 - 3 } & ${ }^{\mathbf{9 0}} \mathbf{S r}$ & ${ }^{\mathbf{1 3 7}} \mathbf{C s}$ \\
\hline Zeolite (shivyrtuin) & $36 \pm 4$ & $<17$ \\
\hline Clinoptilolite & $62 \pm 6$ & $<12$ \\
\hline Diatomite (Ural) & $60 \pm 4$ & $<10$ \\
\hline Shungite & $121 \pm 12$ & $40 \pm 7$ \\
\hline Vermiculite & $48 \pm 5$ & $<18$ \\
\hline Perlite & $137 \pm 9$ & $<11$ \\
\hline White Clay & $71 \pm 5$ & $<24$ \\
\hline Radionite & $88 \pm 8$ & $<13$ \\
\hline Sapropel & $57 \pm 4$ & $24 \pm 4$ \\
\hline Polyphepan & $30 \pm 3$ & $<11$ \\
\hline Lignohumate & $45 \pm 3$ & $13 \pm 1$ \\
\hline Amorphous silicon dioxide & $15 \pm 2$ & $<3$ \\
\hline
\end{tabular}

By the method of atomic adsorption spectrometry in the study of the TE content in a sample of Ural diatomite (Senior Research Scientist, Candidate of Veterinary Sciences N.A. Brichko) it was found that the cadmium content is more than $3.5 \mathrm{mg} / \mathrm{kg}$, and lead - more than $100 \mathrm{mg} / \mathrm{kg}$ at the residues level for mineral additives, respectively, 0.4 and $50 \mathrm{mg} / \mathrm{kg}$ ("Temporary maximum permissible level of the content of certain chemical elements and gossypol in feed for farm animals and feed additives", MRL 123-4/281-8-87 of 07.08.1987).

The relevance of conducting continuous radiation sanitary and hygienic control of veterinary surveillance facilities will increase simultaneously with the growth of nuclear energy use in industry, power generation, medicine, science and, consequently, with an increase in the risk of technological accidents and environmental pollution. Therefore, when developing feed additives and sorption-detoxifying complex preparations for long-term use in animal husbandry, it is necessary to take into account the background levels of radionuclides in the applied substances of natural origin, as well as in the 
finished forms of veterinary agents. In addition, the control of the radionuclides content is necessary for the extraction and processing of natural raw materials and feed additives and drugs production with its use, since external contamination and inhaled intake of RS with dust in the human organism can contribute to the radiation burden of the production personnel.

Equally important are the background content levels of TE and ecotoxicants of other groups from the perspective of compliance with the requirements of occupational health and hygiene standard in the extraction and processing of natural raw materials.

In this regard, it is rational to pay more attention to the study of detoxifying and biologically active substances that have been processed to reduce the natural level of ecotoxicants of radiation and chemical nature, and substances of artificial origin obtained synthetically, containing minimal amounts of toxic and ballast components. Modified and synthetic zeolites and clays (for example, montmorillonite, bentonite, amadeite), preparations based on amorphous silicon dioxide, products of chitin processing, pectins and other sorptiondetoxifying and biologically active substances are also of considerable interest [13].

Currently, pharmacological agents and feed additives containing silicon compounds are increasingly used, the effectiveness of which is due, on the one hand, to the physiological activity of this minor-nutrient element, and, on the other, to the high sorption properties of amorphous silicon dioxide, which makes it possible to use it both as a detoxifying agent and as a carrier for the active ingredients in premixes and feed additives [14-16].

On the market of sorbents and feed additives there are products of the BriS series containing amorphous silicon dioxide (FC, FF, Antitox, Activ brands) produced by Tovesorb, premixes "Kovelos-sorb", "Kovelosmixosorb", "Kovelos Energy" (LLC "Ecokremny"), preparations aerosil, sorbosil, thixosil, etc. LLC "Silika" is a supplier of pyrogenic silicon dioxide of foreign production under the trademarks: Aerosil and HDK (Germany), Orisil (Ukraine). Wacker HDK T40 is a brand of pyrogenic silicon dioxide with the highest specific surface area, used as a highly dispersed carrier of catalysts and active substances in pharmacology [17].

Feed additives based on silicon dioxide are used for various types of farm animals, including poultry and fisheries, as effective sorption agents and bio-available sources of silicon to normalize energy metabolism, improve growth and weight indicators, increase reproductive capacity, obtain high-quality offspring, eliminate delays in the growth and development of young animals. The prophylactic dose for animals is $0.1-0.4 \mathrm{~g} / \mathrm{kg}$, for the intoxication treatment - at a dose of $0.4-1.0 \mathrm{~g} / \mathrm{kg}$ of live weight for $3-5$ days $[18,19]$.

In medical and veterinary practice, silicon dioxide preparations are used as pharmacological detoxifying agents (polysorb MP and VP, white coal, white soot, nanosorbent HB-1, etc.). Combined additives, including clinoptilolite, humates, yeast cell walls, etc have also been created on the basis of silicon dioxide.

A significant advantage of amorphous silicon dioxide preparations is that it is an artificial mineral product obtained from high-purity sodium silicate. This eliminates the presence of foreign impurities in the composition of the preparation, which is typical for sorbents of natural origin, for example, zeolites, diatomite, glauconite, which are a complex mixture of natural components, including heavy metals and radioactive isotopes. The absence of such impurities made it possible to use sorbents based on silicon dioxide not only as feed additives and pharmaceutical products but also in the food industry (as a means for filtering and refining liquids, as a food additive E 551, preventing caking and clumping) and in cosmetology.

Taking into account the above-mentioned, we can conclude that artificial amorphous silicon dioxide is one of the most effective, safe, and economically available sorbing substances produced by the domestic industry. Therefore, it should be considered as a promising agent for application as the main non-selective detoxifier and a carrier of additional active substances in the composition of complex sorption-detoxifying agents used in the combined intake of xenobiotics of different toxicological action mechanisms to prevent the transition of ecotoxicants to animal organs and tissues, reduce the negative impact on the organism and obtain safe products for the consumer.

\section{Conclusion}

Based on the scientific literature data and the results of our research, we should conclude that it is necessary to strictly control the ecotoxicants content in raw materials used for the production of veterinary agents and feed additives. As an anthropogenic impact on the environment increases, such control will become particular relevant.

To reduce the risk of radioactive substances and chemical toxicants entering the animal organisms with feed additives and veterinary pharmacological agents, it is necessary to expand research in the use of innovative substances with a minimum content of toxic and ballast components and introduce technologies for their use in agricultural production.

\section{References}

1. A.M. Shadrin, Natural zeolites of Siberia in animal husbandry, veterinary medicine and environmental protection (Novosibirsk, 2004) $116 \mathrm{p}$.

2. V.P. Myazin, Yu.V. Pavlenko, A.N. Hatkova, Comprehensive assessment of zeolite tuffs of the Eastern Trans-Baikal to determine the main directions of their use in the national economy, Mining Inform. and Analyt. Bull. 9, 207-213 (2001)

3. V.I. Kovalenko, O.N. Prokofiev, Radiation-hygienic assessment of the use of natural zeolites as feed additives to cattle, Abstr. of the Republ. Conf. Natural Zeolites of Russia: Medical and biological properties and application in agriculture, Vol. 2 (November 25-27, 1991) (Novosibirsk, 1992), p. 5 
4. V.I. Bogdanova, I.A. Belitsky, B.A. Fursenko, On the question of the possible toxicity of zeolitecontaining rocks associated with dealumination, Abstr. of the Republ. Conf. Natural Zeolites of Russia: Medical and biological properties and application in agriculture, Vol. 2 (November 25-27, 1991) (Novosibirsk, 1992), pp. 14-17

5. Yu.V. Pavlenko, Assimilation of toxic elements and calculation of their maximum allowable concentration in zeolite-containing rocks, Abstr. of the Republ. Conf. Natural Zeolites of Russia: Medical and biological properties and application in agriculture, Vol. 2 (November 25-27, 1991) (Novosibirsk, 1992), pp. 17-23

6. L.N. Pylev, I.E. Valamina, Carcinogenic activity of zeolite-containing tuffs of Shivyrtuy deposit in Siberia, Sib. J. of Oncol., 6(1), 12-16 (1995)

7. V.N. Frash, N.N. Vanchugova, E.E. Rosenberg, L.G. Malysheva, A.S. Fomina, S.V. Shcherbakov, On the possibility of accumulation of toxic effects during experimental exposure to zeolites, Abstr. of the Republ. Conf. Natural Zeolites of Russia: Medical and biological properties and application in agriculture, Vol. 2 (November 25-27, 1991) (Novosibirsk, 1992), pp. 12-14

8. A.A. Gaidash, V.Ya. Apchel, E.V. Ivchenko, V.I. Bely, V.V. Bakakin, Impact of zeolite tufas oral intake on the body, Bull. of the Russ. Milit. Med. Acad., 1(53), 115-123 (2016)

9. B.F. Radchikov, N.V. Kurtina, D.V. Gurina, Physiological state and productivity of heifer replacements when using local sources of protein, energy and biologically active substances in the diets, Zootechn. Sci. of Belarus, Sci. papers coll. Zhodzina, 47(2), 208-215 (2012)

10. S.Yu. Mironov, S.S. Petrov, Distribution of heavy metals according to the sapropel profile and assessment of its environmental safety, Approbat., 6(45), 204-206 (2016)

11. D.S. Chukurov, Ya.V. Medvedeva, O.V. Nikitin, Investigation of applicability of Almetyevsk water reservoir bottom sediments for use as an organic fertilizer, Russ. J. of Appl. Ecol., 1, 22-27 (2016)
12. I.V. Gravel, Necessity for safety evaluation of medicinal herbs by contents of ecotoxicants, Bull. of the Sci. Centre for Expert Evaluat. of Med. Prod., 2, 37-39 (2012)

13. I.E. Epifanova, V.G. Epimakhov, Intake mercury, lead and arsenic with feeds and their accumulation (bioconcentration) in cattle and sheep organism, Bull. of Sci. and Pract., 5(3), 173-186 (2019), Retrieved from: https://doi.org/10.33619/24142948/40/23

14. E.V. Arhitskaya, I.V. Iakushkin, The Practical Significance and Efficiency of Applying the Chelators in Animal Husbandry, Res. and Sci. Electr. J. of Omsk SAU, Special Issue 2 (2016), Retrieved from: http://ejournal.omgau.ru/index.php/spetsvypusk-2/31spets02/400-00149

15. L.A. Mansurova, O.V. Fedchishin, V.V. Trofimov, T.G. Zelenina, L.E. Smolyanko, Physiological Role of Silicium, Sib. Med. J., 7, 16-18 (2009)

16. A.S. Mustafina, Influence of nanoscale silicon oxide on the concentration of heavy metals in the body of agricultural poultry, Proc. of the Int. Sci. and Pract. Conf. Future-proof agricultural and food innovations (June 6-7, 2019) (Volgograd, 2019), pp. 180-183

17. Yu.O. Velyaev, A.P. Sitak, N.A. Mitrokhin, N.I. Pokintelitsa, I.A. Prokopenko, Possibilities of application of amorphous silica obtained from domestic natural aluminosilicate raw materials as a food additive E551, Innov., 4(13), 6-13 (2018)

18. S.I. Kononenko, N.A. Yurina, D.A. Yurin, A.Z. Utizhev, The efficiency of the sorbent based on amorphous silicon dioxide in the rations of cattle, Bull. of Don Agrar. Sci., 4(36), 83-89 (2016)

19. S.I. Kononenko, N.A. Yurina, A.A. Danilova, I.R. Tletseruk, V.A. Ovsepyan, Formation of productive qualities of broiler chickens with an increase in the biological value of feeding, Proc. of the All-Russ. Sci. and Pract. Conf. with Int. Particip. Problems and prospects of agricultural development in the South of Russia (September 27-28, 2018) (Maykop, 2018), pp. 379-384 